\title{
Correlations Between IELTS and TOEIC Scores
}

\section{Masaya Kanzaki \\ Kanda University of International Studies}

\section{Reference Data}

Kanzaki, M. (2021). Correlations between IELTS and TOEIC scores. In P. Clements, R. Derrah, \& P. Ferguson (Eds.), Communities of teachers \& learners. JALT. https://doi.org/10.37546/ JALTPCP2020-49

This study investigated correlations between scores on the International English Language Testing System (IELTS) test and the Test of English for International Communication (TOEIC) in an attempt to determine the practicality of substituting TOEIC scores for IELTS scores as a language requirement for English-medium universities. Eighty-four university students took part in the study, and their IELTS and TOEIC scores were analyzed. Significant correlations were found between scores for the same skill on the two tests ( $r$ between .50 and .69). When different skill scores were added together, the correlations between the combined scores were even higher ( $r$ between 77 and .81). In light of these results, I argue for using the TOEIC as a proxy for the IELTS test.

本研究では、英語で授業が行われる大学への入学条件として、Test of English for International Communication (TOEIC) の 得点をInternational English Language Testing System (IELTS)の得点で代替することの実用性を探るため、、IELTSとTOEICの 得点間の相関を調べた。84名の大学生が本研究に参加し、彼らのIELTSとTOEICの得点を分析した。両テストの同じ技能スコア 間には有意な相関があった(相関係数.50〜.69)。異なる技能スコアが加算されると、合計得点間の相関は更に高かつた(相関 係数.77〜.81)。これらの結果に基づき、TOEICをIELTSの代替として使うことに関して賛成の立場から論ずる。

nglish-medium universities around the world typically require prospective 1 international students whose native languages are not English to have a certain score or above on an English proficiency test, such as the International English Language Testing System (IELTS) test and Test of English as a Foreign Language Internet-Based Test (TOEFL iBT). The problem with these academically oriented tests is that they are prohibitively expensive for economically disadvantaged students. Although more affordable tests, such as the Test of English for International Communication (TOEIC), are available, few universities accept them as valid English language qualifications. The purpose of this study was to investigate correlations between IELTS and TOEIC scores with the expectation that universities might reconsider their English requirement policies if scores of a currently accepted test and an affordable alternative are shown to be closely related.

Here are brief descriptions of the two tests. The IELTS test, which is jointly administered by the British Council, IDP IELTS Australia, and Cambridge Assessment English, started in 1989, superseding the English Language Testing Service (ELTS; Charge \& Taylor, 1997). Two types of IELTS are available: IELTS Academic, which tests English skills needed to take English-medium courses at university, and IELTS General Training, which tests everyday English skills required in workplace and social situations. Note that these differences are in the reading and writing sections only and that the two types of IELTS share the same listening and speaking sections. In other words, the listening and speaking sections of the IELTS Academic are not as academically oriented as the reading and writing sections. The IELTS can be taken either on paper or on a computer, although the speaking section is only available in a live interview format with an examiner. The IELTS is administered around the world, with 3.5 million tests taken in 2018 and over 10,000 organizations using IELTS scores for selection purposes (IELTS, 2019a). As of March 2021, the cost to take the IELTS in Japan was 25,380 yen.

The TOEIC, developed by Educational Testing Service (ETS) to assess everyday English skills used in the workplace, started in 1979 with the TOEIC Listening and Reading test (TOEIC LR), and the TOEIC Speaking and Writing tests (TOEIC SW) were added in 2006 (Powers \& Schmidgall, 2018). Note that the TOEIC LR is one test with listening and reading sections as subcomponents, whereas TOEIC SW refers to two different tests, which can be taken together or separately. In regard to test administration, two types of TOEIC programs are offered in Japan: the Public Testing Program (PP) and the Institutional Testing Program (IP). While the Institute for International Business 
Communication (IIBC), the Japanese administrator of the TOEIC, organizes PP tests directly, each institution administers IP tests with support from IIBC. (For more details about the differences between PP and IP, see Educational Testing Service, 2019a.) The TOEIC LR is used extensively in Japan, with 2.2 million tests taken in 2019 across the country (Institute for International Business Communication, 2020a). By comparison, far fewer people take the TOEIC SW in Japan, with only 37,800 tests taken in 2019 (Institute for International Business Communication, 2020b). As of March 2021, the cost to take the PP versions of the TOEIC LR and TOEIC SW tests in Japan were 6,490 yen and 10,450 yen, respectively.

In previous studies, IELTS scores have been compared with scores of other English proficiency tests, including TOEFL iBT (Educational Testing Service, 2010), the Duolingo English Test (Bézy \& Settles, 2015), the Global Test of English Communication Computer-based Test (Kim, Smith, \& Chin, 2017), and the Pearson Test of English, Academic (PTE Academic; Clesham \& Hughes, 2020). However, to my knowledge, no study comparing IELTS and TOEIC scores has been published. This study is therefore a valuable addition to score comparison research on the IELTS test.

\section{Method}

\section{Participants}

The participants in this study were 84 students (63 female and 21 male) who were attending a private university specializing in foreign languages in the Kanto region. Among them, 24 were in their 1st year, 20 in their 2nd, 23 in their 3rd, and 17 in their 4 th. In terms of fields of study, there were 49 English language majors, 22 international communication majors, seven Spanish language majors, five international business majors, and one Korean language major.

They took part in the study in exchange for a monetary reward. Informed consent was obtained from all the participants. The objectives of the study, as well as the related procedures and requirements, were explained to them before they filled out a consent form. The project was cleared by the university's institutional review board.

\section{Materials}

A paper-based version of the IELTS Academic test and the three TOEIC (IP) tests were used in this study.

\section{IELTS}

The IELTS test has four sections: listening, reading, speaking, and writing. In the listening section, test takers listen to two conversations and two monologues and answer 40 questions of various types, such as multiple choice, matching, and short answer. In the reading section, test takers read three passages having a total of between 2,150 and 2,750 words and answer 40 questions of various types, such as multiple choice, true or false, and short answer. In both the listening and reading sections, raw scores out of 40 are converted to scale scores of between 0 and 9 with increments of 0.5 points.

The speaking section is a face-to-face interview with an examiner and consists of three parts: introduction and general questions on familiar topics, an individual long turn, and a two-way discussion. The writing section consists of two writing tasks: the first is to describe, summarize, or explain some information presented in a graph, table, or chart, and the second is to write an essay in response to an opinion or problem. In both the speaking and writing sections, certified examiners assess the test taker's performance, and the scores are reported in the range of 0 to 9 with increments of 0.5 points.

In addition to the four section scores, overall scores of between 0 and 9 with increments of 0.5 points are reported. An overall score is the average of the four section scores, rounded to the nearest full or half point. (For more details about test format and scoring, see IELTS, 2019a, 2019b, and 2019c.)

The reliability coefficients (Cronbach's alphas) of the listening and reading scores have been made public. They were .88 for both sections in Charge and Taylor (1997), between .82 and .91 for both sections in the 1998/1999 IELTS Annual Review (as cited in Boddy, 2001), and .91 for the listening section and .90 for the reading section in the 2014 IELTS Annual Review (as cited in Alshammari, 2016). However, IELTS has stopped reporting reliability coefficients, the reasons for which are unknown, and its current publications do not include any such data. To my knowledge, IELTS has never published reliability coefficients of the speaking and writing scores but Charge and Taylor (1997) and the 1998/1999 IELTS Annual Review (as cited in Boddy, 2001) claimed that the reliability of these sections is maintained through the training, certification, and monitoring of examiners.

\section{TOEIC}

The TOEIC LR is a paper-based, machine-scored examination consisting of a listening section and a reading section. Each section consists of 100 multiple-choice questions, and raw scores out of 100 are converted to scaled scores of between 5 and 495 with 
increments of 5 points. The listening section has four parts, whereas the reading section has three. (For more details about the TOEIC LR, see Educational Testing Service, 2019b.)

The TOEIC Speaking test is a computer-based examination requiring test takers to sit in front of a screen while wearing a headset with a microphone. They speak into the microphone, and what they say is recorded and sent to certified raters for evaluation.

There are 11 questions on the test, and scores are reported in the range of 0 to 200 with increments of 10 points.

The TOEIC Writing test is also a computer-based examination. Instructions are provided on the screen, and test takers use a keyboard to type their responses, which are then sent to certified raters for evaluation. There are eight questions on the test, and scores are reported in the range of 0 to 200 with increments of 10 points. (For more details about the TOEIC SW, see Educational Testing Service, 2019c.)

According to ETS publications (Educational Testing Service, 2019d, 2019e), the reliability indices of the listening, reading, speaking, and writing scores are .90 (KR-20), .90 (KR-20), .80 (stratified coefficient alpha), and .82 (alternate forms testretest reliability), respectively. According to the same sources, the standard error of measurement for the listening, reading, speaking, and writing scores are 25,25, 13, and 17 scaled score points, respectively.

Procedures

The participants took the four sections of the IELTS test on campus on September 7 , 2019, and the three TOEIC tests on campus on September 10, 2019. After the test results became available, the scores were analyzed.

\section{Results}

\section{Inclusion of IELTS Total Scores}

IELTS total scores, which are the simple sums of the four section scores, are included in score analyses, although they are not shown in test reports. Note that total scores are different from overall scores, which are the rounded average of the four section scores. The reason for including total scores is that unrounded simple sums can show differences between scores more accurately than rounded figures. For example, the total scores 19, 19.5, 20, and 20.5 are transformed into the same overall score of 5 when averaged and rounded.

\section{Descriptive Statistics}

Table 1 displays the descriptive statistics for the IELTS and TOEIC scores. Note that some adjustments were made when the TOEIC total scores were calculated; to make the four skill scores equally weighted in the total, the TOEIC SW scores were divided by 400 (the highest possible TOEIC SW score) and multiplied by 990 (the highest possible TOEIC LR score) before being added to the TOEIC LR scores.

Table 1

Descriptive Statistics for Scores $(N=84)$

\begin{tabular}{lcrrrrrr}
\hline & $\begin{array}{c}\text { Possible } \\
\text { Scores }\end{array}$ & Mean & $S D$ & Min & Max & Skewness & Kurtosis \\
\hline IELTS L & $0-9$ & 5.30 & .68 & 3.5 & 7.0 & 0.10 & 0.35 \\
IELTS R & $0-9$ & 5.46 & .93 & 3.5 & 8.0 & 0.30 & -0.10 \\
IELTS S & $0-9$ & 5.54 & .82 & 3.5 & 8.0 & 0.20 & 0.26 \\
IELTS W & $0-9$ & 5.33 & .51 & 3.5 & 6.0 & -0.67 & 0.68 \\
IELTS & $0-36$ & 21.63 & 2.33 & 16.0 & 27.0 & 0.08 & -0.07 \\
Total & & & & & & & \\
IELTS & $0-9$ & 5.45 & .611 & 4.0 & 7.0 & 0.13 & -0.16 \\
Overall & & & & & & & \\
TOEIC L & $5-495$ & 383.15 & 76.28 & 145 & 495 & -0.89 & 0.78 \\
TOEIC R & $5-495$ & 330.06 & 80.19 & 85 & 470 & -0.82 & 0.70 \\
TOEIC S & $0-200$ & 137.74 & 19.35 & 90 & 190 & 0.21 & 0.34 \\
TOEIC W & $0-200$ & 144.76 & 22.41 & 70 & 190 & -0.92 & 1.88 \\
TOEIC LR & $10-990$ & 713.21 & 146.96 & 270 & 965 & -0.80 & 0.58 \\
TOEIC & $10-1,980$ & $1,412.40$ & 221.58 & 715.75 & $1,855.75$ & -0.76 & 1.21 \\
Total & & & & & & & \\
\hline
\end{tabular}

Note. $\mathrm{L}=$ listening, $\mathrm{R}=$ reading, $\mathrm{S}=$ speaking, $\mathrm{W}=$ writing,$S D=$ standard deviation, Min = lowest score, Max = highest score. 


\section{JALT2020}

COMMUNITIES OF

\section{Histograms}

Figures 1 to 4 show histograms of the IELTS total scores, IELTS overall scores, TOEIC LR scores, and TOEIC total scores, respectively. The distributions of these scores deviate from the normal distribution to some degree, which is reflected in the skewness values in Table 1. In order to address the non-normality of the distributions, bootstrapping was performed when the correlations between the scores were calculated.

Figure 1

Histogram of the IELTS Total Scores.

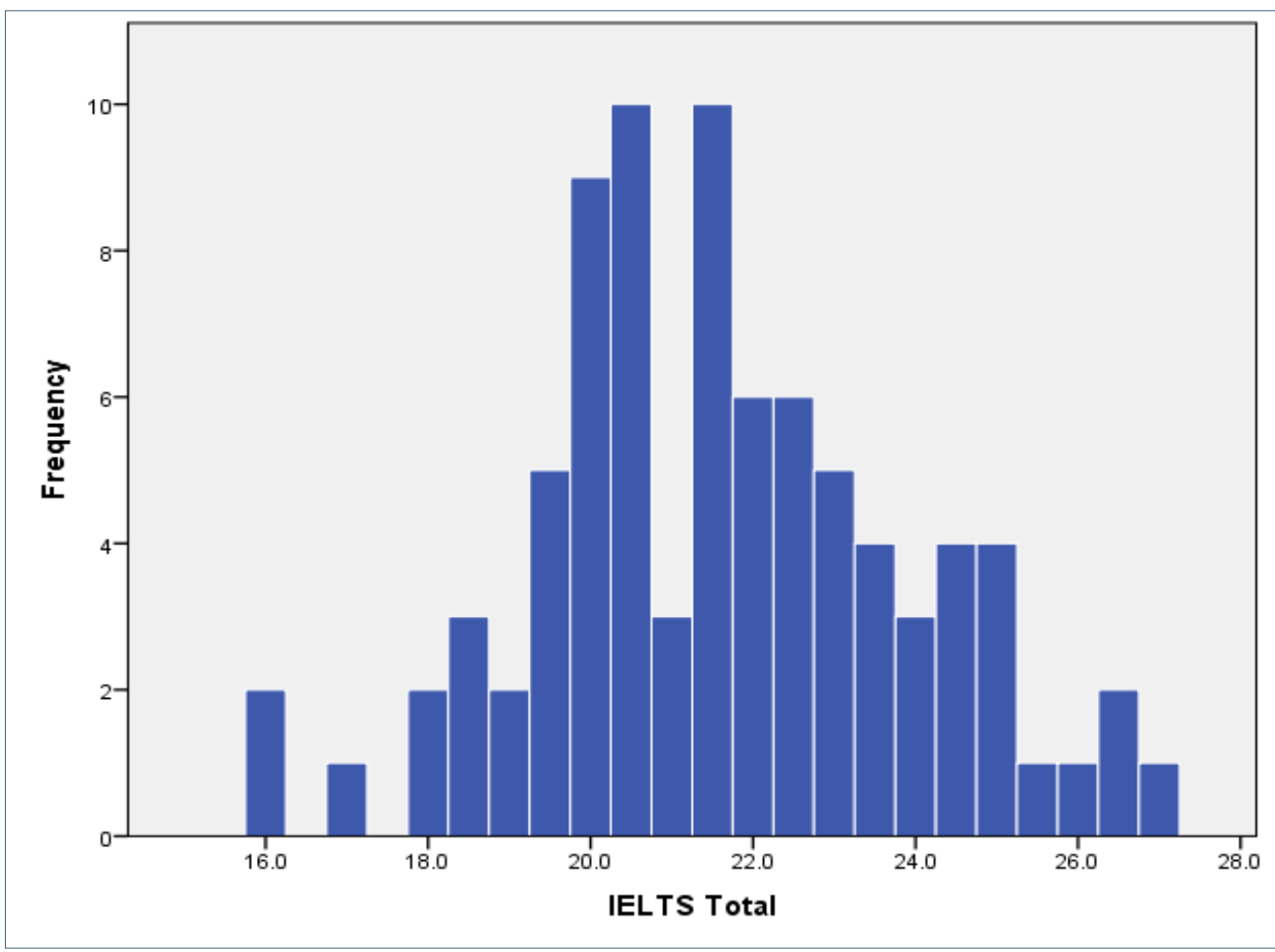

Figure 2

Histogram of the IELTS Overall Scores.

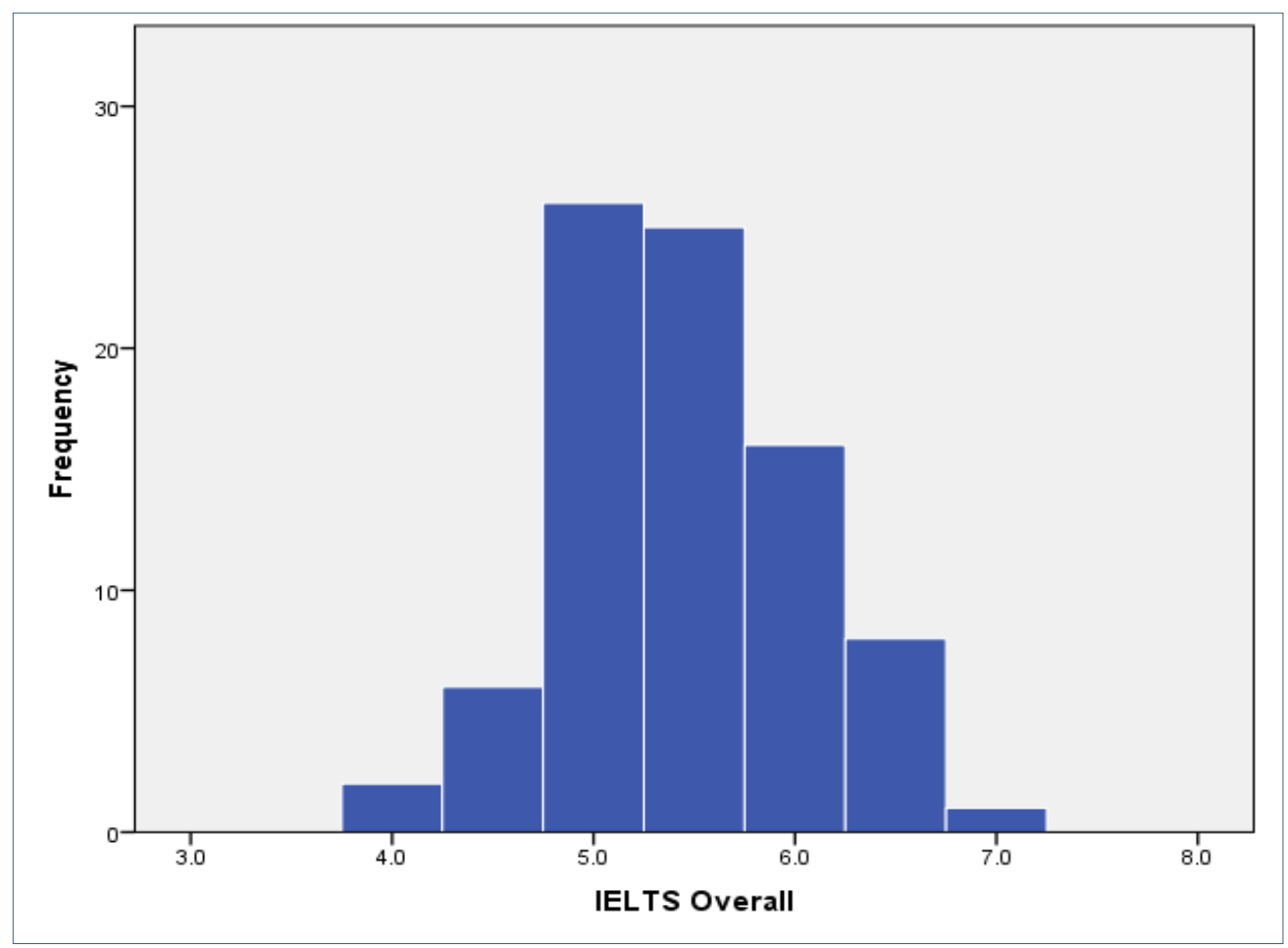




\section{JALT2020}

COMMUNITIES OF
TEACHERS \& IEARNERS

Figure 3

Histogram of the TOEIC LR Scores.

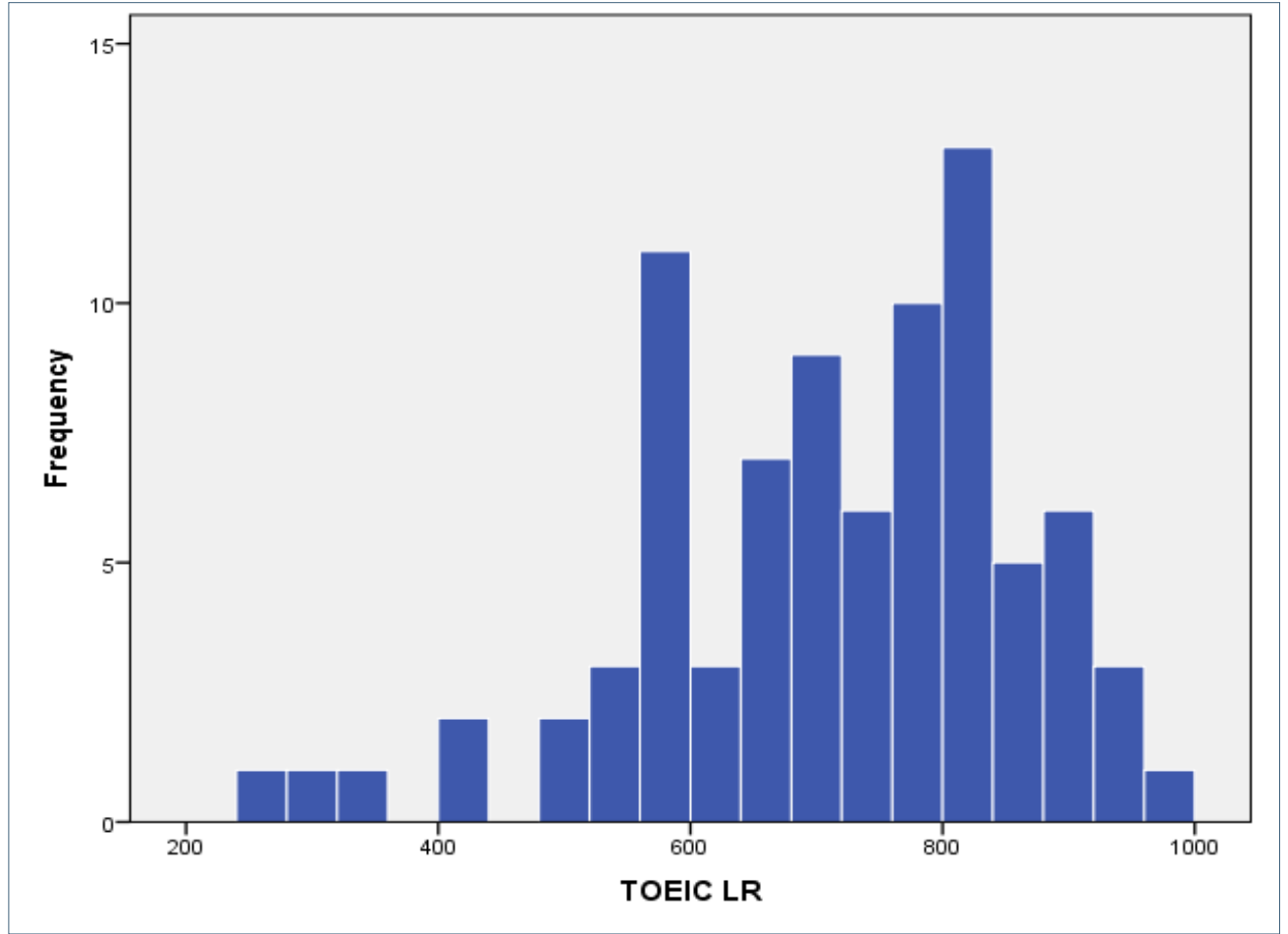

Kanzaki: Correlations Between IELTS and TOEIC Scores

Figure 4

Histogram of the TOEIC Total Scores.

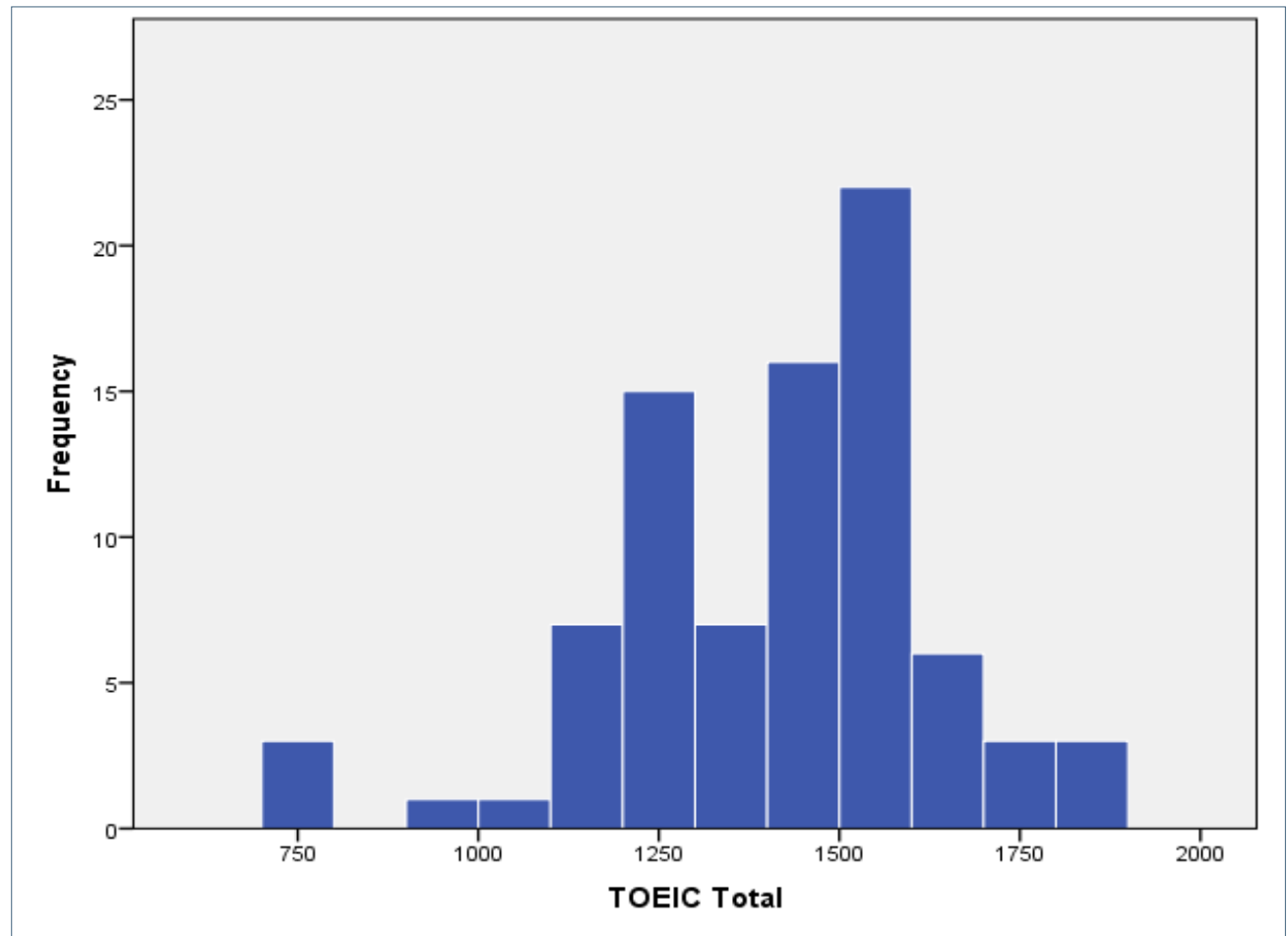

\section{Correlations}

Pearson's $r$ correlations between the same skill scores of IELTS and TOEIC and between four pairs of combined scores were calculated. As the scores did not meet the assumption of normality, bootstrapping was performed with 1,000 samples, and biascorrected and accelerated bootstrap 95\% confidence intervals were obtained for all correlations using IBM SPSS Bootstrapping. Table 2 presents the correlations between the same skill scores of IELTS and TOEIC. All correlations, between .50 and .69 , were significant $(p<.001)$. As the listening and speaking sections of the IELTS Academic test are also used for the General Training test, the two sections are not particularly 
academically oriented and are thus similar, in this respect, to TOEIC. However, the reading score correlation was higher than the listening score correlation, even though the IELTS reading is academically oriented. Similarly, the writing score correlation was higher than the speaking score correlation, even though the IELTS writing is academically oriented.

Table 2

Same Skill Score Correlations of IELTS and TOEIC $(N=84)$

\begin{tabular}{lcccc}
\hline & Listening & Reading & Speaking & Writing \\
\hline Correlation & $.64 *$ & $.69 *$ & $.50 *$ & $.58^{*}$ \\
& {$[.49, .76]$} & {$[.55, .78]$} & {$[.31, .65]$} & {$[.41, .62]$} \\
\hline
\end{tabular}

Note. $* p<.001$ (two-tailed). BCa bootstrap $95 \%$ Cls reported in brackets.

Table 3 presents the correlations between four pairs of combined scores: the IELTS total and TOEIC LR scores, IELTS overall and TOEIC LR scores, IELTS total and TOEIC total scores, and IELTS overall and TOEIC total scores. All correlations, between .77 and .81 , were significant $(p<.001)$

Table 3

Correlations Between Four Pairs of Combined Scores $(N=84)$

\begin{tabular}{ccccc}
\hline & IELTS total & IELTS overall & IELTS total & IELTS overall \\
& -TOEIC LR & -TOEIC LR & -TOEIC total & -TOEIC total \\
\hline Correlation & $.78^{*}$ & $.77^{*}$ & $.81^{*}$ & $.79 *$ \\
& {$[.66, .85]$} & {$[.66, .84]$} & {$[.72, .88]$} & {$[.70, .87]$} \\
\hline
\end{tabular}

Note. $* p<.001$ (two-tailed). BCa bootstrap $95 \%$ Cls reported in brackets.

Figures 5 to 8 display scatterplots that visually present the relationships between each pair of scores in Table 3. In Figures 6 and 8, the dots in the scatterplots are aligned in some places to form horizontal lines because the IELTS overall scores are rounded to the nearest full or half point. As a result, the pairs with the IELTS overall scores in Figures 6 and 8 produced weaker correlations than their counterparts with the IELTS total scores in Figures 5 and 7.
Figure 5

Scatterplot of the IELTS Total and TOEIC LR Scores.

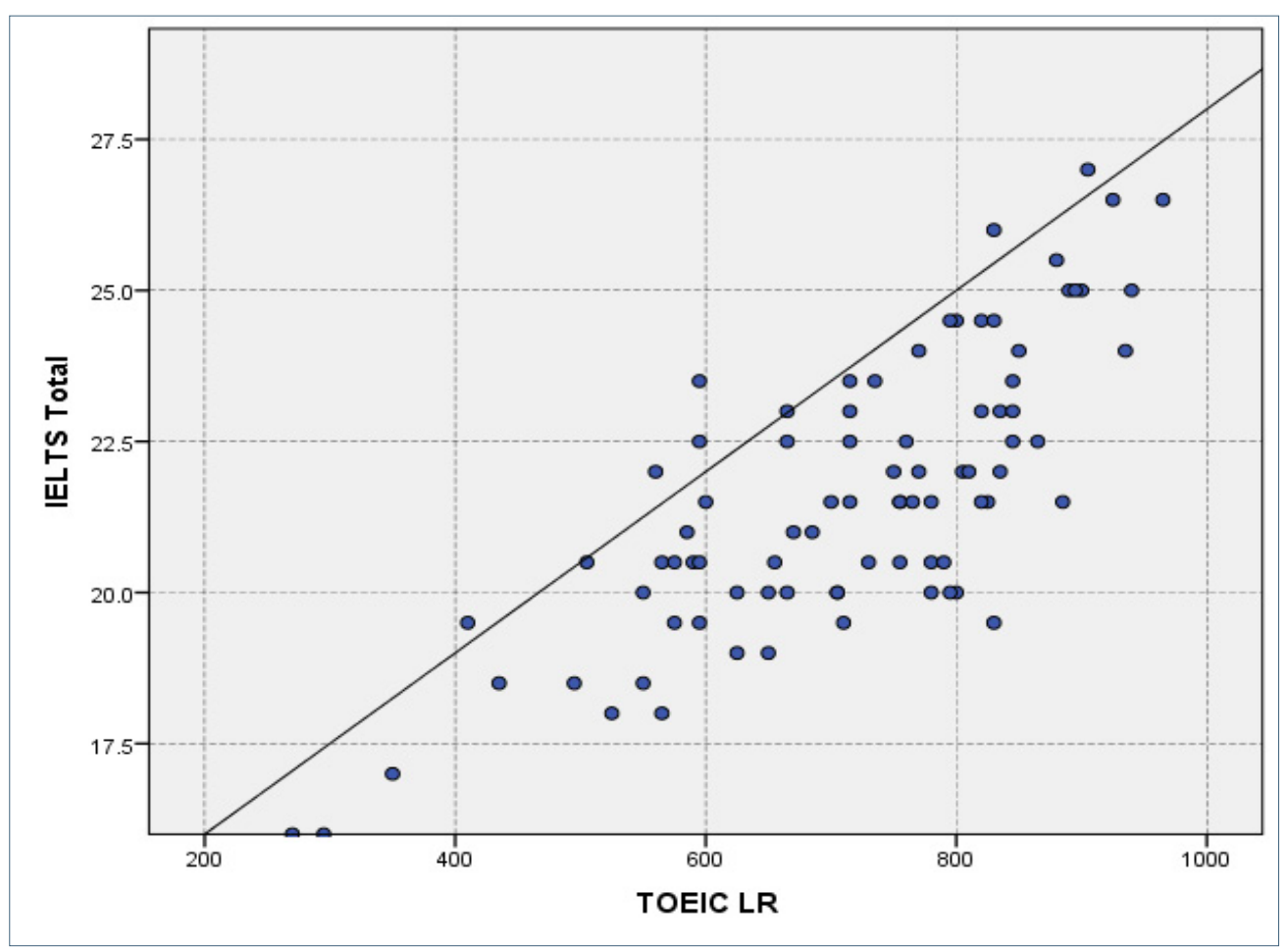




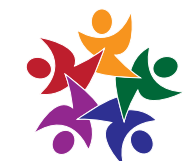 \\ JALT2020}

COMMUNITIES OF
TEACHERS \& LEARNERS

JAPAN ASSOCIATION FOR LANGUAGE TEACHING • JALT2020 »Communities of Teachers \& Learners

\section{Figure 6}

Scatterplot of the IELTS Overall and TOEIC LR Scores.

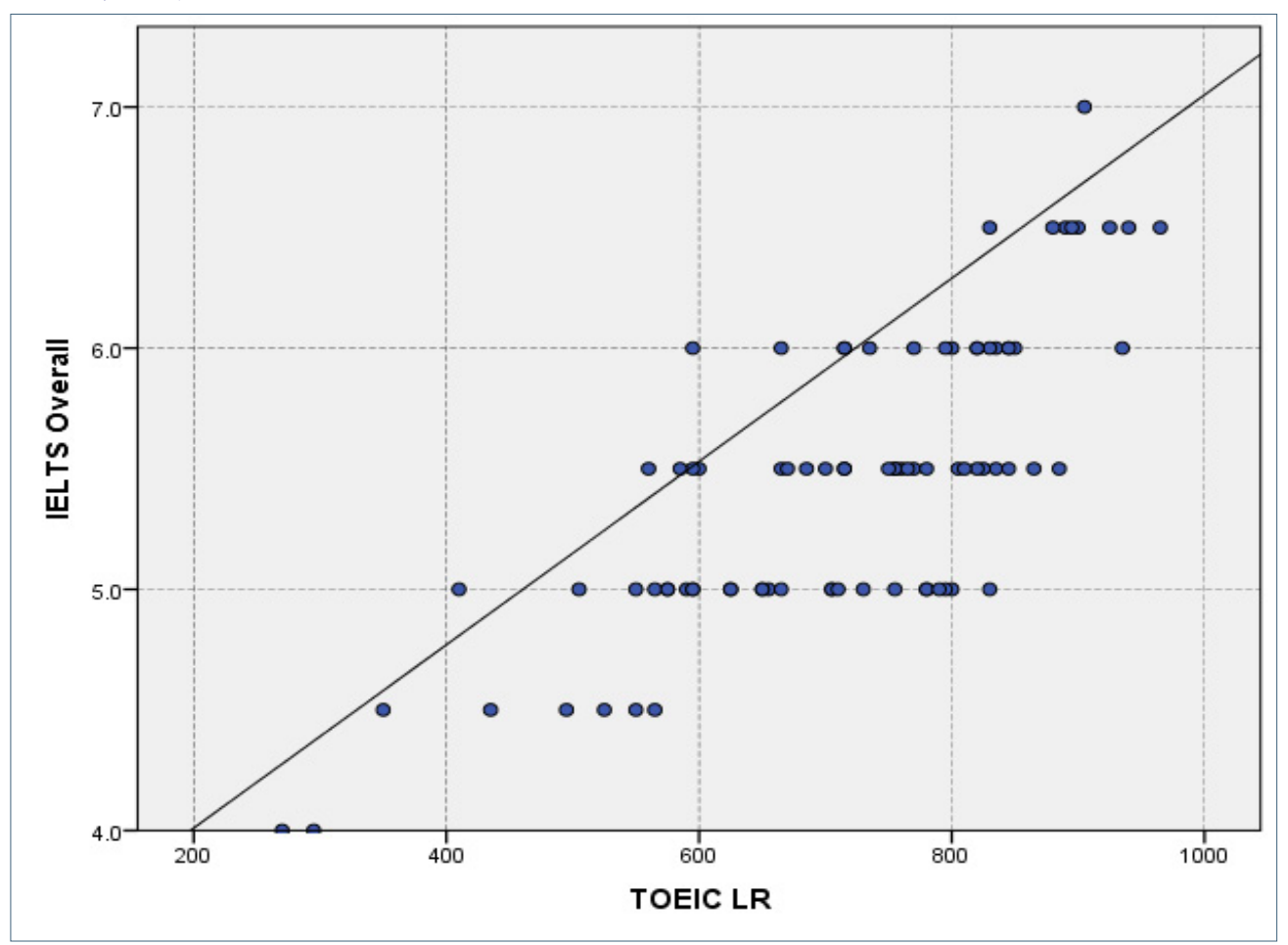

Figure 7

Scatterplot of the IELTS Total and TOEIC Total Scores.

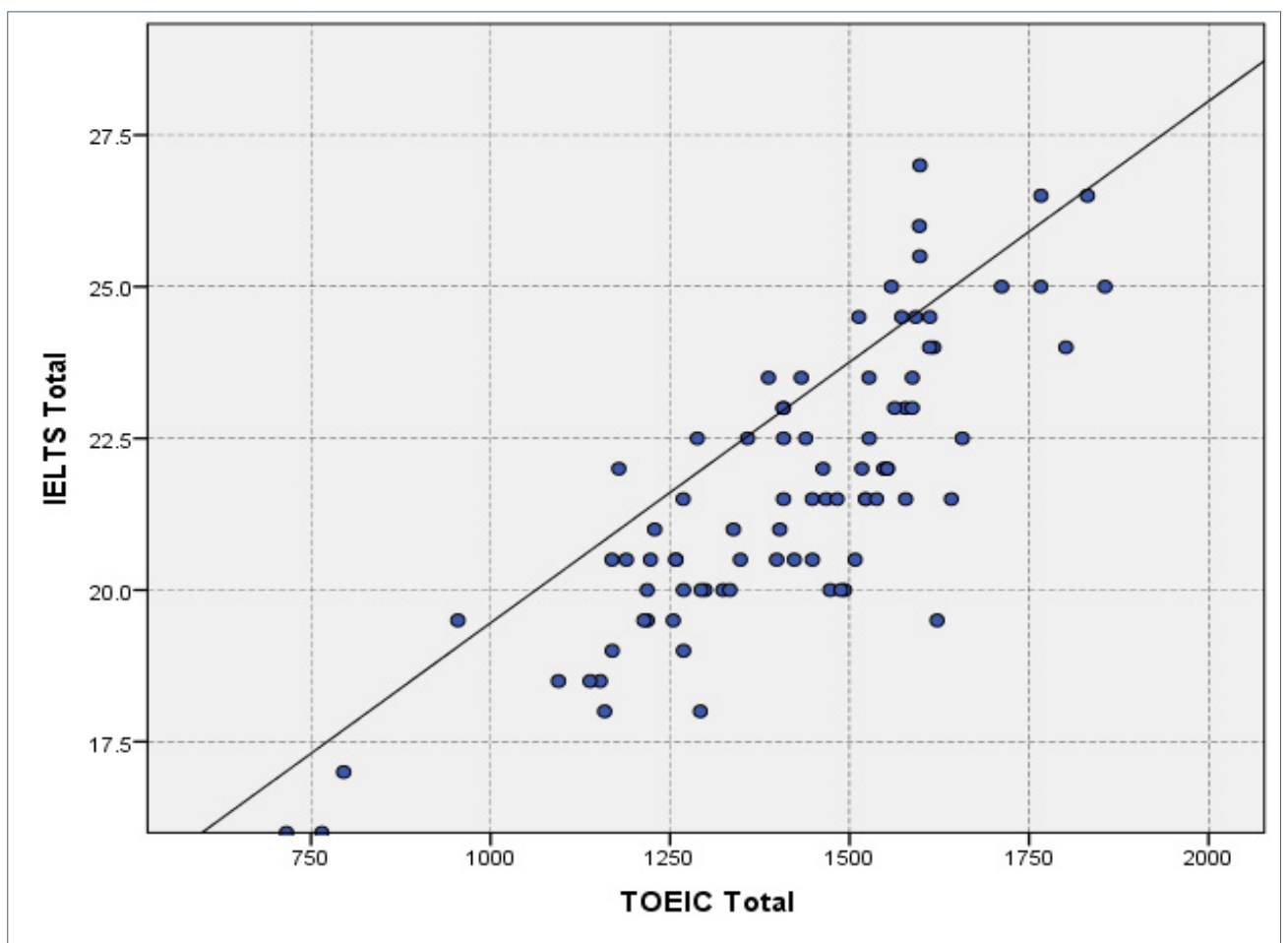




\section{JALT2020}

COMMUNITIES OF
TEACHERS \& IEARNERS

\section{Figure 8}

Scatterplot of the IELTS Overall and TOEIC Total Scores.

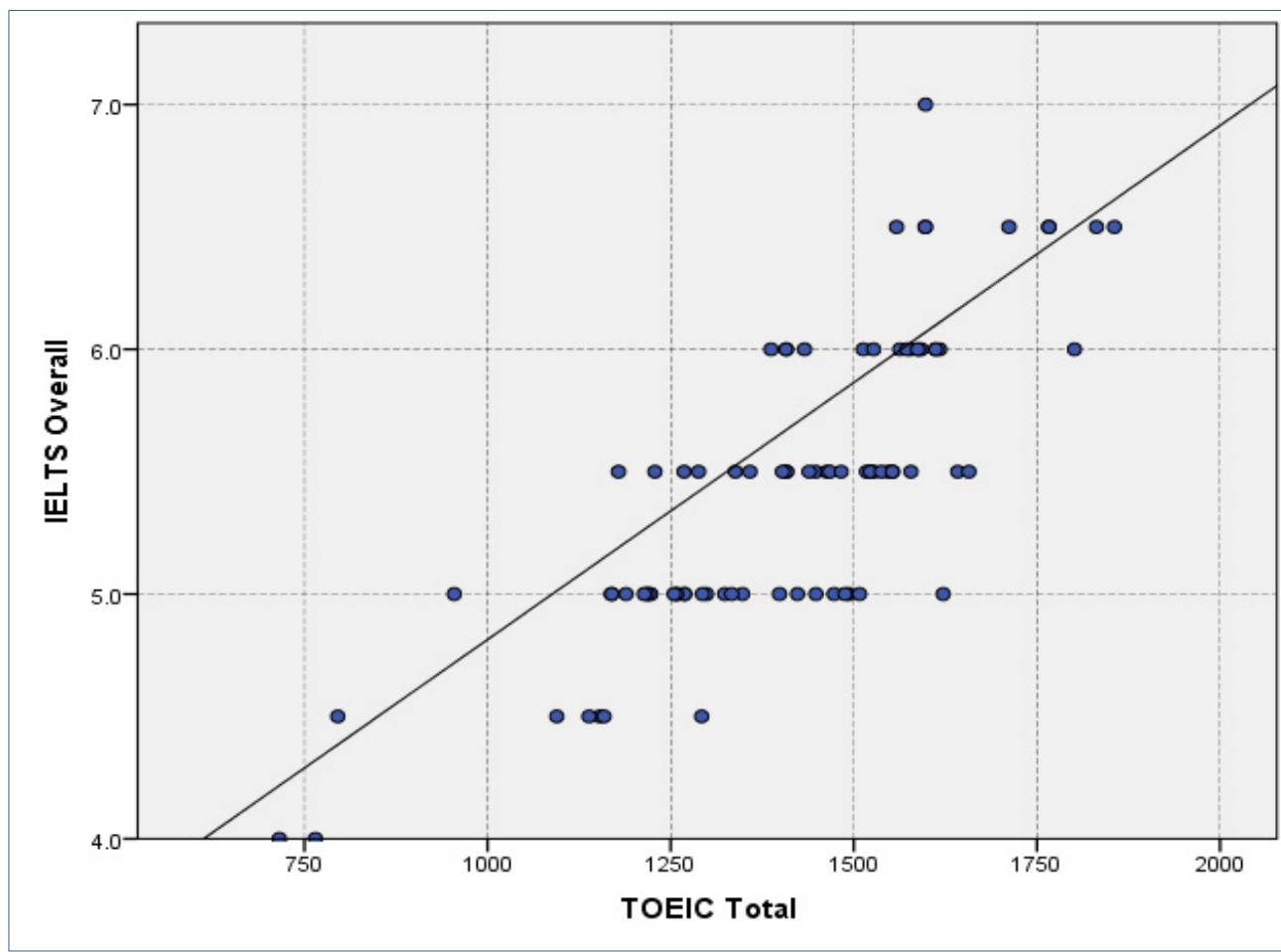

\section{Discussion}

It is up to debate as to whether the correlations found in this study are high enough for the TOEIC to be used as an alternative to the IELTS. Dorans $(2000,2004)$ proposed that a correlation of at least .866 is required for one set of scores to be a valid predictor of another, arguing that a $50 \%$ reduction in uncertainty is achieved when the correlation is .866. The correlations found in this study are lower than that. Nevertheless, some tests are used as substitutes for others even when the correlations between their scores are not that high. For example, the correlations between IELTS scores and scores on the TOEFL iBT and PTE Academic, both of which are accepted as alternatives to IELTS by many English-medium universities, were reported to be lower than .866 (Clesham \& Hughes, 2020; Educational Testing Service, 2010). Tables 4 and 5 present the correlations between the IELTS and TOEFL iBT scores reported in Educational Testing Service (2010) and those between the IELTS and PTE Advanced scores reported in Clesham and Hughes (2020) along with those between the IELTS and TOEIC scores found in this study. Table 4 shows the same skill score correlations, while Table 5 shows the correlations between IELTS overall scores and the combined scores of the other tests, including the TOEIC LR scores. Note that the number of samples for the PTE Academic is lower in Table 4 than in Table 5. This is because 171 of the 562 participants in Clesham and Hughes (2020) did not report section scores for the IELTS test.

Table 4

Same Skill Score Correlations Between IELTS and TOEFL iBT, PTE Academic, and TOEIC

\begin{tabular}{lcccc}
\hline & Listening & Reading & Speaking & Writing \\
\hline IELTS-TOEFL iBT $(N=1,153)$ & $.63^{\mathrm{a}}$ & $.68^{\mathrm{a}}$ & $.57^{\mathrm{a}}$ & $.44^{\mathrm{a}}$ \\
IELTS-PTE Academic $(N=391)$ & $.66^{\mathrm{b}}$ & $.68^{\mathrm{b}}$ & $.42^{\mathrm{b}}$ & $.60^{\mathrm{b}}$ \\
IELTS-TOEIC $(N=84)$ & .64 & .69 & .50 & .58 \\
\hline
\end{tabular}

Note. Data in the first two rows are from Educational Testing Service (2010) and Clesham and Hughes (2020)

Table 5

Combined Score Correlations Between IELTS and TOEFL iBT, PTE Academic, and TOEIC

\begin{tabular}{lc}
\hline & IELTS Overall \\
\hline TOEFL iBT Total $(N=1,153)$ & $.73^{\mathrm{a}}$ \\
PTE Academic Overall $(N=562)$ & $.74^{\mathrm{b}}$ \\
TOEIC Total $(N=84)$ & .79 \\
TOEIC LR $(N=84)$ & .77 \\
\hline
\end{tabular}

Note. Data in the first two rows are from Educational Testing Service $(2010)^{a}$ and Clesham and Hughes $(2020)^{b}$. 
Regarding the same-skill score correlations in Table 4, the highest reading score correlation was between the IELTS and TOEIC scores. Also, for the IELTS-TOEIC pair the listening score correlation was higher than that of the IELTS-TOEFL iBT pair, the speaking score correlation higher than that of the IELTS-PTE Academic pair, and the writing score correlation higher than that of the IELTS-TOEFL iBT pair. Among the four correlations between the combined scores in Table 5, the correlation between the IELTS overall and TOEIC total scores is the highest and the correlation between the IELTS overall and TOEIC LR scores is the second highest. Considering that the IELTS overall scores are more closely correlated with the TOEIC total and TOEIC LR scores than with the TOEFL iBT and PTE Academic scores, the TOEIC can serve as an alternative to the IELTS as a language requirement for international students-either the three TOEIC tests together or the TOEIC LR by itself.

If the TOEIC is to be used as an alternative to the IELTS, a concordance table that links the scores of the two tests is needed. However, the sample size of this study is 84 , and the linking of scores cannot be done effectively when the sample size is small (Holland, Dorans, \& Petersen, 2006). In addition, the IELTS overall scores obtained in this study are clustered in a narrow range, as shown in Table 6 as well as in Figure 2. Almost 80 percent of the scores are within the range of 5 and 6 .

Table 6

Frequencies of IELTS Overall Scores $(N=84)$

\begin{tabular}{lc}
\hline IELTS Overall & Frequency \\
\hline 7 & 1 \\
6.5 & 8 \\
6 & 16 \\
5.5 & 25 \\
5 & 26 \\
4.5 & 6 \\
4 & 2 \\
\hline
\end{tabular}

Despite these limitations, I conducted an equipercentile analysis using the Rank-andPercentile function of MS Excel in an attempt to create a concordance table; percentile ranks of the IELTS and TOEIC scores were calculated, and the scores were linked based on their percentile ranks. As the IELTS overall scores were concentrated within the range of 5 and 6 , only the three scores of 5, 5.5, and 6 were linked to the TOEIC scores. Also, some manual adjustments were made when the upper and lower limits of the TOEIC scores for the three IELTS scores were determined, and this is because not all the scores were a good match based solely on percentile ranks. Decimal points of the TOEIC total scores were rounded to the closest whole numbers in the process. Table 7 is the resulting concordance table. As it only covers three IELTS scores, it may not have much practical use. Moreover, due to the small sample size, the score linkages may not be accurate.

Table 7

Concordance Table for IELTS and TOEIC Scores

\begin{tabular}{ccc}
\hline IELTS Overall & TOEIC Total & TOEIC LR \\
\hline 6 & 1,550 and above & 810 and above \\
5.5 & $1,400-1,549$ & $705-805$ \\
5 & $1,160-1,399$ & $550-700$
\end{tabular}

\section{Conclusion}

The results showed that the IELTS overall scores correlated with the TOEIC total scores at .79 and with the TOEIC LR scores at .77. These correlations are higher than those between the IELTS and TOEFL iBT scores in Educational Testing Service (2010) and those between the IELTS and PTE Academic scores in Clesham and Hughes (2020). Since TOEFL iBT and PTE Academic are often accepted as valid alternatives to the IELTS by English-medium universities, I suggest that the TOEIC be accepted as well. If universities are more flexible about which tests can be used for English language requirements, it will benefit prospective international students from economically disadvantaged backgrounds. However, before the TOEIC can be used as a proxy for the IELTS, the linkages between the scores of the two tests should be more comprehensively understood. The partial concordance table in this paper is not adequate, and therefore further research with a much larger sample size is needed.

\section{Data Sharing}

The IELTS and TOEIC scores used in this study are available at http://bit.ly/pcp2020mk. 
JALT2020

COMMUNITIES OF
TEACHERS \& IEARNERS

\section{Acknowledgements}

This study was supported by JSPS KAKENHI Grant Number 17K03018 and a KUIS Research Grant.

\section{Bio Data}

Masaya Kanzaki teaches at Kanda University of International Studies. His research interests include language testing, vocabulary acquisition, and corpus linguistics. $<$ kanzaki-m@kanda.kuis.ac.jp>

\section{References}

Alshammari, M. M. (2016). IELTS academic reading module test: Validity and reliability. British Journal of English Linguistics, 4(2), 26-37. Retrieved from http://www.eajournals.org/wp-content/ uploads/lELTS-Academic-Reading-Module-Test-Validity-and-Reliability1.pdf

Bézy, M., \& Settles, B. (2015). The Duolingo English Test and East Africa: Preliminary linking results with IELTS \& CERF (Duolingo Research Report DRR-15-01). Retrieved from https:// s3.amazonaws.com/duolingo-papers/reports/DRR-15-01.pdf

Boddy, N. (2001). The revision of the IELTS speaking test. Shiken, 5(2), 2-5. Retrieved from https:// hosted.jalt.org/test/PDF/Boddy1.pdf

Charge, N., \& Taylor, L. B. (1997). Recent developments in IELTS. ELT Journal, 51(4), 374-380. https://doi.org/10.1093/elt/51.4.374

Clesham, R., \& Hughes, S. R. (2020). 2020 concordance report PTE Academic and IELTS Academic. Retrieved from https://pearsonpte.com/wp-content/uploads/2020/12/2020-concordanceReport-for-research-pages.pdf

Dorans, N. J. (2000). Distinctions among classes of linkages (College Board Research Note RN-11). College Board. Retrieved from https://files.eric.ed.gov/fulltext/ED562636.pdf

Dorans, N. J. (2004). Equating, concordance, and expectation. Applied Psychological Measurement, 28(4), 227-246. https://doi.org/10.1177/0146621604265031

Educational Testing Service. (2010). Linking TOEFL iBT scores to IELTS scores-A research report. Retrieved from https://www.ets.org/s/toefl/pdf/linking_toefl_ibt_scores_to_ielts_scores.pdf

Educational Testing Service. (2019a). Comparing TOEIC institutional and public testing programs. Retrieved from https://www.ets.org/s/toeic/pdf/comparing-institutional-and-public-testing.pdf

Educational Testing Service. (2019b). Examinee handbook: TOEIC Listening \& Reading test. Retrieved from https://www.ets.org/s/toeic/pdf/examinee-handbook-for-toeic-listening-reading-testupdated.pdf
Educational Testing Service. (2019c). Examinee handbook: TOEIC Speaking \& Writing tests. Retrieved from https://www.ets.org/s/toeic/pdf/speaking-writing-examinee-handbook.pdf

Educational Testing Service. (2019d). Score user guide: TOEIC Listening \& Reading test. Retrieved from https://www.ets.org/s/toeic/pdf/toeic-listening-reading-test-user-guide.pdf

Educational Testing Service. (2019e). Score user guide: TOEIC Speaking \& Writing tests. Retrieved from https://www.ets.org/s/toeic/pdf/toeic-sw-score-user-guide.pdf

Holland, P. W., Dorans, N. J., \& Petersen, N. S. (2006). Equating test scores. Handbook of Statistics, 26, 169-203. https://doi.org/10.1016/S0169-7161(06)26006-1

IELTS. (2019a). Guide for teachers: Test format, scoring, and preparing students for the test. Retrieved from https://www.ielts.org/-/media/publications/guide-for-teachers/ielts-guide-for-teachers-uk. ashx?la=en

IELTS. (2019b). Guide for agents: Information for education and migration agents around the world Retrieved from https://www.ielts.org/-/media/publications/guide-for-agents/ielts-guide-foragents-uk.ashx?la=en

IELTS. (2019c). Information for candidates: Introducing IELTS to test takers. Retrieved from https:// www.ielts.org/-/media/publications/information-for-candidates/ielts-information-forcandidates-english-uk.ashx

Institute for International Business Communication. (2020a). TOEIC Listening and Reading test 受験者の推移 [The changes in the numbers of yearly test takers of the TOEIC Listening and Reading test]. Retrieved from https://www.iibc-global.org/library/default/toeic/official_data/lr/pdf/ lr_transition_2019.pdf

Institute for International Business Communication. (2020b). TOEIC Speaking and Writing tests 受験者の推移 [The changes in the numbers of yearly test takers of the TOEIC Speaking and Writing tests]. Retrieved from https://www.iibc-global.org/library/default/toeic/official_data/sw/pdf/ sw_transition_2019.pdf

Kim, M., Smith, W. Z., \& Chin, T. Y. (2017). Validation and linking scores for the Global Test of English Communication: White paper. Retrieved from https://www.benesse.co.jp/gtec/schoolofficials/ research/pdf/doc-2016-02.pdf

Powers, D. E. \& Schmidgall, J. E. (2018). The TOEIC test: A brief history. In D. E. Powers \& J. E. Schmidgall (Eds.), The research foundation for the TOEIC tests: A compendium of studies: Vol. 3 (pp. 1.1-1.5). Retrieved from https://www.ets.org/s/toeic/pdf/research-compendium.pdf 